\title{
Quantitative changes in mitochondria of spinal ganglion neurons in aged rabbits
}

\author{
M. Ledda, C. Martinelli and E. Pannese* \\ Institute of Histology, Embryology and Neurocytology, University of Milan, Milan, Italy
}

[Received 4 October 2000; Revised 11 December 2000; Accepted 15 December 2000]

\begin{abstract}
Within the context of our research on the agerelated structural changes in spinal ganglia, we studied the mitochondria of the neuronal perikaryon in the spinal ganglia of 12-, 42-, and 79-month-old rabbits. Both the volume of the perikaryon and the total mitochondrial mass within the perikaryon increased significantly passing from young adult to old animals. Hence, there is no net loss of mitochondria in these neurons with age. Since, however, the volume of the perikaryon increased by more than $63 \%$ while the total mitochondrial mass within the perikaryon increased by only $18 \%$, the mean percentage of perikaryal volume occupied by mitochondria decreased with age. This decrease is only in very minor part a consequence of lipofuscin accumulation, so that the ratio between the total mitochondrial mass and the functionally active volume of cytoplasm decreased with age. Possible causes of this decrease are discussed briefly. Moreover, while the mitochondrial structure did not change, mitochondrial size increased with age. Finally, in each of the three age groups both the mean percentage volume of mitochondria and the mean mitochondrial size were very similar in large light and in small dark neurons. () 2001 Elsevier Science Inc.
\end{abstract}

KEY WORDS: Dorsal root ganglia, Sensory neurons, Ageing, Oryctolagus cuniculus.

\section{INTRODUCTION}

Evidence that mitochondria are important in the ageing process, particularly in postmitotic cells, has accumulated in recent years (for reviews, see $[2,10,14,15,23,24]$ ). For this reason, within the context of our research on the age-related structural changes in spinal ganglia we have paid particular attention to the mitochondria of the neurons of these ganglia. As far as we are aware, only structural alterations in these organelles have so far been reported in these neurons of old animals [21,22]. By contrast, the quantitative changes with age of these organelles in spinal ganglion neurons seem to have been neglected. In the present study, therefore, we have sought mainly to assess the quantitative aspects of the age-related changes in these organelles.

\section{MATERIALS AND METHODS}

\section{Animals}

Rabbits (Oryctolagus cuniculus) aged 12 months (two animals, one male and one female, $3.4-3.5 \mathrm{~kg}$ body weight), 42 months (two animals, one male and one female, $3.6-3.8 \mathrm{~kg}$ body weight) and 79 months (two animals, one male and one female, $4.0-4.2 \mathrm{~kg}$ body weight) were used. The rabbits were treated according to the European Community Council Directive (86/609/EEC) for the care and use of laboratory animals. The dates of birth of these animals were documented; all had been raised by a specialist rabbit breeder with particular attention to hygiene and regular veterinary inspections and had been fed an unrestricted diet. Because the life span of the normal healthy Oryctolagus is 60-72 months [5] or 84-96 months [25], the 12-month-old rabbits we studied were young adults, the 42-month-old rabbits were middle-aged animals and the 79-month-old rabbits were aged animals. Furthermore, the end of fertility is usually considered to mark the onset of senescence and female rabbits are not normally fertile after 60 months, so that the 79-month-old animals are to be considered aged also from this point of view.

\section{Tissue Preparation}

The animals were perfused transcardially with a solution containing $2 \%$ formaldehyde and $2 \%$ glutaraldehyde in $0.1 \mathrm{M}$ sodium cacodylate buffer ( $\mathrm{pH}$ 7.3) under deep anaesthesia with Nembutal $(80 \mathrm{mg} / \mathrm{kg})$. After fixation for about $3 \mathrm{~h}$, the thoracic spinal ganglia were removed, washed in cacodylate buffer $(0.2 \mathrm{M}, \mathrm{pH} 7.3)$ for $2 \mathrm{~h}$ and then postfixed on ice for $1.5 \mathrm{~h}$ in $2 \% \mathrm{OsO}_{4}$, buffered with 0.1 $\mathrm{M}$ sodium cacodylate. The specimens were washed in distilled water, stained with $2 \%$ aqueous uranyl acetate, dehydrated in alcohol and embedded in Epon-Araldite resin. Several semithin sections were prepared from each ganglion and stained with $0.5 \%$ toluidine blue in $1 \%$ sodium borate. They were then examined in the light microscope to check the quality of fixation. Only the best preserved ganglia were used and none of the nerve cell bodies in these ganglia showed signs of swelling or shrinkage. Overall, 60 ganglia (10 for each animal) were used for this study.

\section{Quantitative Analysis of Mitochondria}

Isotropic uniform random (IUR) sections were obtained following the orientator procedure [13]. For each ganglion a single IUR thin section (about $0.25 \times 0.20 \mathrm{~mm}$ ) was photographed under the electron microscope. Each section was photographed in its entirety at a magnification of $2,500 \times$ and the negatives printed to a final magnification of $10,000 \times$. A montage of $60-70$ prints was

* Address for correspondence: Prof. Ennio Pannese, Viale S. Michele del Carso 15, I-20144 Milano, Italy. Fax: +39-0270635928; E-mail: ennio.pannese@unimi.it 


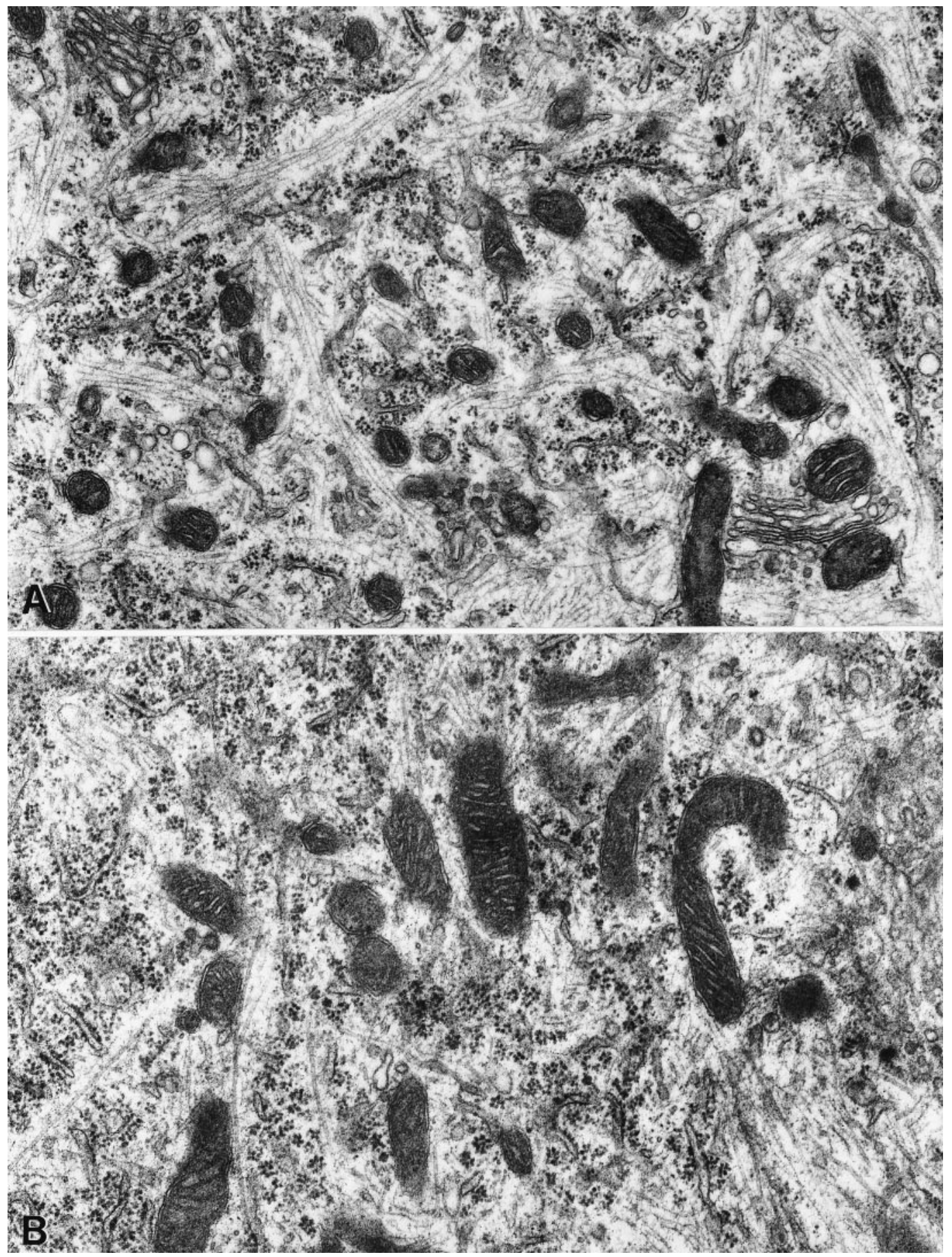

FIG. 1. Perikaryal portions of spinal ganglion neurons from a young adult (A) and an old (B) rabbit. Electron micrographs, $28,000 \times$.

necessary to reconstruct each section. A transparent sheet containing a series of points spaced at $1 \mathrm{~mm}$ intervals was randomly positioned over the photomontage. Next a sheet of cardboard containing uniform-sized $(10 \times 5 \mathrm{~cm})$, systematically arranged windows was placed over the transparent sheet and photomontage. For each section, all the points falling on the neuronal perikaryon $\left(\mathrm{P}_{\mathrm{n}}\right)$ within each window were counted, as were all the points lying on the mitochondria $\left(\mathrm{P}_{\mathrm{nm}}\right)$. The percentage of perikaryal volume occupied by mitochondria $\left(\mathrm{V}_{\mathrm{vnm}}\right)$ was calculated from the following formula: $\mathrm{V}_{\mathrm{vnm}}=\mathrm{P}_{\mathrm{nm}} \times 100 / \mathrm{P}_{\mathrm{n}}$. The mean value of $\mathrm{V}_{\mathrm{vnm}}$ $( \pm \mathrm{SD})$ was calculated for each rabbit.

To obtain information on the size of the mitochondria, the number of test points lying on each mitochondrion within each window was determined. The mean number of points $( \pm S D)$ lying on a mitochondrion was then calculated for each animal. This number gives an indication of the size of the mitochondria under study. 
TABLE 1

MEAN PERCENTAGE OF PERIKARYAL VOLUME OCCUPIED BY MITOCHONDRIA AND MEAN SIZE OF MITOCHONDRIA

\begin{tabular}{|c|c|c|c|c|c|c|}
\hline Rabbit & $\begin{array}{c}\text { Age } \\
\text { (Months) }\end{array}$ & $\begin{array}{c}\text { No. of } \\
\text { Ganglia } \\
\text { Examined }\end{array}$ & $\begin{array}{c}\text { Total No. of } \\
\text { Points Lying on } \\
\text { the Perikaryon } \\
\left(\mathrm{P}_{\mathrm{n}}\right)\end{array}$ & $\begin{array}{l}\text { No. of Points } \\
\text { Lying on } \\
\text { Mitochondria } \\
\quad\left(\mathrm{P}_{\mathrm{nm}}\right)\end{array}$ & $\begin{array}{l}\text { Mean } \%( \pm \mathrm{SD}) \text { of } \\
\text { Perikaryal Volume } \\
\text { Occupied by } \\
\text { Mitochondria }\left(\mathrm{V}_{\mathrm{vnm}}\right)\end{array}$ & $\begin{array}{c}\text { Mean No. of } \\
\text { Points }( \pm \text { SD) } \\
\text { Lying on a } \\
\text { Mitochondrion }\end{array}$ \\
\hline \multicolumn{7}{|c|}{ Values for each rabbit } \\
\hline 1 & 12 & 10 & 477550 & 49086 & $10.35 \pm 1.34$ & $2.98 \pm 0.49$ \\
\hline 2 & 12 & 10 & 507186 & 54048 & $10.83 \pm 1.92$ & $2.99 \pm 0.46$ \\
\hline 3 & 42 & 10 & 481100 & 37912 & $8.72 \pm 2.14$ & $3.28 \pm 0.45$ \\
\hline 4 & 42 & 10 & 482832 & 40740 & $8.71 \pm 0.69$ & $3.26 \pm 0.45$ \\
\hline 5 & 79 & 10 & 556746 & 44972 & $7.80 \pm 1.46$ & $3.59 \pm 0.82$ \\
\hline 6 & 79 & 10 & 591916 & 43312 & $7.48 \pm 1.39$ & $3.60 \pm 0.73$ \\
\hline \multicolumn{7}{|c|}{ Values for each age group } \\
\hline Young adult & & 20 & 984736 & 103134 & $10.61 \pm 1.67^{\mathrm{a}}$ & $2.99 \pm 0.47^{\mathrm{a}}$ \\
\hline Intermediate & & 20 & 963932 & 78652 & $8.71 \pm 1.59^{\mathrm{b}}$ & $3.27 \pm 0.45^{\mathrm{b}}$ \\
\hline Old & & 20 & 1148662 & 88284 & $7.65 \pm 1.43^{\mathrm{c}}$ & $3.60 \pm 0.77^{\mathrm{c}}$ \\
\hline
\end{tabular}

The differences between ${ }^{\mathrm{a}}$ and ${ }^{\mathrm{b}}$, between ${ }^{\mathrm{b}}$ and ${ }^{\mathrm{c}}$ and between ${ }^{\mathrm{a}}$ and ${ }^{\mathrm{c}}$ are significant $(p<0.05)$.

The part of each ganglion left after the preparation of the IUR thin section was used to determine the volume of the neuronal perikarya. To this end, a series of semithin sections ( $1 \mu \mathrm{m}$ thick) parallel to the IUR thin section was cut for each ganglion. Each section was stained with $0.5 \%$ toluidine blue in $1 \%$ sodium borate and photographed in its entirety at a magnification of $350 \times$; the prints (final magnification $1,000 \times$ ) were montaged and ordered in the same sequence as the serial sections. Two hundred and fortytwo nerve cell bodies in the young adults, 231 in the middle-aged animals and 235 in the old rabbits were used. The volume of each nerve cell body was determined by measuring, with the aid of a digitizing tablet connected to a computer, the surface area of each of its profiles within the series of sections, multiplying these values by the section thickness and summing the results obtained. The same procedure was used to determine the volume of the cell nucleus. The volume of the perikaryon was obtained by subtracting the nuclear volume from the cell body volume. The mean volume of the perikaryon was then calculated for each rabbit.

From the mean volume of the perikaryon and the percentage of that volume occupied by mitochondria, the total mitochondrial mass within the perikaryon was calculated for each rabbit.

\section{Statistical Analysis}

The values obtained for the rabbits in each age group were compared to establish whether they differed significantly. The mean values of the age groups were then compared. The statistical comparisons employed the two-tailed Student's $t$-test (differences with $p<0.05$ were considered significant) and for each value the 95\% confidence limits were calculated. All data analyses were carried out using a statistical graphics program (Statgraphics software STSC).

\section{RESULTS}

The structure of the mitochondria conformed to literature descriptions of these organelles (e.g., see [16]) and did not differ in the three age groups. In particular, swollen or degenerating mitochondria were absent in all preparations (Fig. 1).

We found that the percentage of perikaryal volume occupied by mitochondria decreased significantly with increasing age while the mitochondrial size increased significantly with age (Table 1). In each of the three age groups, the mean percentage of perikaryal volume occupied by mitochondria and the mean size of the mitochondria were very similar in large light and in small dark neurons. Furthermore, the volume of the neuronal perikaryon increased significantly with age and the total mitochondrial mass within the perikaryon increased significantly passing from young adult to old rabbits (Table 2). However, the volume of the neuronal perikaryon increased by more than $63 \%$ while the total mitochondrial mass increased by $18 \%$ passing from young adult to old rabbits.

\section{DISCUSSION}

\section{Percentage Volume of Mitochondria in Young Adult Rabbits}

In the spinal ganglion neurons of young adult rabbits the mitochondria occupied $10.6 \%$ of the perikaryal volume. This percentage is similar to those reported for other regions of the nervous system: hypoglossal nucleus of the rabbit [8], supraoptic nucleus of the rat [3], olfactory bulb of the rat [7] and superior cervical ganglion of the sheep [4]. By contrast, distinctly larger values (about $14 \%$ and $21 \%$, respectively) have been reported in pyramidal cells of the rat auditory cortex [17] and in ventral horn neurons of the rat spinal cord [9]. The reasons for these differences are unclear. In the young adult rabbits we studied the mean percentage volume of mitochondria was very similar in large light and in small dark neurons. Similarly, no difference was found in the mean percentage volume of mitochondria that could be related to cell size in the superior cervical ganglion of the sheep [4].

\section{Percentage Volume of Mitochondria: Changes with Age}

In the present study we found that in spinal ganglion neurons of the rabbit the percentage of perikaryal volume occupied by mitochondria decreased significantly with increasing age. A similar result was obtained for neurons of the rat vestibular ganglion [12] and for non-nervous tissues $[6,20]$. By contrast, other studies found that the percentage of cytoplasmic volume occupied by mitochondria remained stable with age in pyramidal cells of the rat auditory cortex [17] and in the rat superior laryngeal nerve [18], but increased from 27 to 30 months in the mitral cells of the rat olfactory bulb [7]. Furthermore, we found that in each of the three age groups the mean percentage volume of mitochondria was very similar for large light and small dark neurons. 
TABLE 2

TOTAL MITOCHONDRIAL MASS WITHIN THE PERIKARYON

\begin{tabular}{|c|c|c|c|c|}
\hline Rabbit & $\begin{array}{c}\text { Age } \\
\text { (Months) }\end{array}$ & $\begin{array}{c}\text { Number of } \\
\text { Ganglia Examined }\end{array}$ & $\begin{array}{l}\text { Perikaryal Volume } \\
\left(\mu \mathrm{m}^{3}, \text { Mean }\right)\end{array}$ & $\begin{array}{l}\text { Total Mitochondrial Mass } \\
\text { Within the Perikaryon } \\
\left(\mu \mathrm{m}^{3}, \text { Mean }\right)\end{array}$ \\
\hline \multicolumn{5}{|c|}{ Values for each rabbit } \\
\hline 1 & 12 & 10 & 14104.72 & 1460.68 \\
\hline 2 & 12 & 10 & 14119.28 & 1529.54 \\
\hline 3 & 42 & 10 & 18791.83 & 1638.65 \\
\hline 4 & 42 & 10 & 19451.15 & 1694.19 \\
\hline 5 & 79 & 10 & 22873.01 & 1785.01 \\
\hline 6 & 79 & 10 & 23351.11 & 1746.89 \\
\hline \multicolumn{5}{|c|}{ Values for each age group } \\
\hline Young adult & & 20 & $14112.12^{\mathrm{a}}$ & $1496.87^{\mathrm{d}}$ \\
\hline Intermediate & & 20 & $19128.63^{\mathrm{b}}$ & $1667.06^{\mathrm{e}}$ \\
\hline Old & & 20 & $23109.01^{\mathrm{c}}$ & $1767.84^{\mathrm{f}}$ \\
\hline
\end{tabular}

The differences between ${ }^{\mathrm{a}}$ and ${ }^{\mathrm{b}}$, between ${ }^{\mathrm{b}}$ and ${ }^{\mathrm{c}}$ and between ${ }^{\mathrm{a}}$ and ${ }^{\mathrm{c}}$ are significant $(p<0.05)$.

There are no significant differences between ${ }^{\mathrm{d}}$ and ${ }^{\mathrm{e}}$ and between ${ }^{\mathrm{e}}$ and ${ }^{\mathrm{f}}$, whereas the difference between ${ }^{\mathrm{d}}$ and ${ }^{\mathrm{f}}$ is significant $(p<0.05)$.

\section{Total Mitochondrial Mass: Changes with Age}

We found that both the volume of the perikaryon and the total mitochondrial mass within the perikaryon increased significantly passing from young adult to old rabbits. Since, however, the perikaryal volume increased by more than $63 \%$ and the total mitochondrial mass increased by $18 \%$, the percentage volume of mitochondria decreased in old animals.

Previous work in our laboratory [11] showed that in rabbit spinal ganglion neurons the percentage of perikaryal volume occupied by lipofuscin is very low, although it does increase with age $(0.36 \%$ at 12 months and $2.55 \%$ at 79 months). Hence, the decrease in the percentage volume of mitochondria we observed in old animals is only in very minor part due to lipofuscin accumulation. It is therefore clear that, in the neurons studied, the ratio between the total mitochondrial mass and the functionally active volume of cytoplasm decreases in old age. This decrease might be a consequence of reduced neuronal energy requirements or due to inability of the mitochondria to adapt their total mass to the functionally active volume of cytoplasm. Since the neurons of old animals are characterized by a decreased ability to respond to high energy demands (e.g., see [19]), the second suggestion appears more likely.

The decrease in the percentage volume of mitochondria with age, considered alone, would seem to suggest that in these neurons mitochondrial degradation prevails over the production of new mitochondria as age increases. However, since the total mitochondrial mass within the perikaryon increases slightly (18\%) passing from young adult to old rabbits, we can conclude that the production of new mitochondria manages to keep ahead of mitochondrial degradation even in old age.

\section{Size of Mitochondria}

Our data showed that the mean number of points falling on a mitochondrion significantly increased with age. Because the mitochondria did not appear swollen in any age group, this finding indicates that mitochondria increase in size with age. Similar findings have been reported in cerebellar synaptic glomeruli [1] and in liver cells $[20,26]$. Tauchi and Sato [20] suggested that this increase is due to a decreased duplicative ability in these organelles. However, the age-related increase in mitochondrial size may not be a general occurrence since Herbener [6] reported that mitochondrial size remained constant throughout life in mouse heart and liver. Finally, we found that the mean mitochondrial size was very similar in large light and in small dark neurons.

\section{ACKNOWLEDGEMENTS}

The authors wish to thank Professor G. Gabella for his useful suggestions and Mr. F. Redaelli for photographic assistance.

\section{REFERENCES}

1. Bertoni-Freddari, C.; Fattoretti, P.; Casoli, T.; Spagna, C.; MeierRuge, W.; Ulrich, J. Morphological plasticity of synaptic mitochondria during aging. Brain Res. 628:193-200; 1993.

2. Cortopassi, G. A.; Wong, A. Mitochondria in cellular aging and degeneration. In: Cadenas, E.; Packer, L., eds. Understanding the process of aging. The roles of mitochondria, free radicals, and antioxidants. New York/Basel: Marcel Dekker; 1999:293-310.

3. Eneström, S.; Hamberger, A. Respiration and mitochondrial content in single neurons of the supraoptic nucleus. A correlative study in osmotic stress. J. Cell Biol. 38:483-493; 1968.

4. Gabella, G.; Trigg, P.; McPhail, H. Quantitative cytology of ganglion neurons and satellite glial cells in the superior cervical ganglion of the sheep. Relationship with ganglion neuron size. J. Neurocytol. 17:753$769 ; 1988$.

5. Harkness, J. E.; Wagner, J. E. The biology and medicine of rabbits and rodents, 2nd ed. Philadelphia: Lea and Febiger; 1983.

6. Herbener, G. H. A morphometric study of age-dependent changes in mitochondrial populations of mouse liver and heart. J. Gerontol. 31: $8-12 ; 1976$.

7. Hinds, J. W.; McNelly, N. A. Aging in the rat olfactory bulb: Quantitative changes in mitral cell organelles and somato-dendritic synapses. J. Comp. Neurol. 184:811-820; 1979.

8. Hudson, G.; Lazarow, A.; Hartmann, J. F. A quantitative electron microscopic study of mitochondria in motor neurones following axonal section. Exp. Cell Res. 24:440-456; 1961.

9. Ishihara, A.; Hayashi, S.; Roy, R. R.; Tamada, Y.; Yokoyama, C.; Ohira, Y.; Edgerton, V. R.; Ibata, Y. Mitochondrial density of ventral horn neurons in the rat spinal cord. Acta Anat. 160:248-253; 1997.

10. Kadenbach, B.; Münscher, C.; Frank, V.; Müller-Höcker, J.; Napiwotzki, J. Human aging is associated with stochastic somatic mutations of mitochondrial DNA. Mutation Res. 338:161-172; 1995.

11. Ledda, M.; Barni, L.; Altieri, L.; Pannese, E. Amount and distribution of lipofuscin in nerve and satellite cells from spinal ganglia of young adult and aged rabbits. J. Submicrosc. Cytol. Pathol. 31:237-246; 1999. 
12. Lyon, M. J.; King, J. M. Aging rat vestibular ganglion: II. Quantitative electron microscopic evaluation. Ann. Otol. Rhinol. Laryngol. 106: 753-758; 1997.

13. Mattfeldt, T.; Mall, G.; Gharehbaghi, H.; Möller, P. Estimation of surface area and length with the orientator. J. Microsc. 159:301-317; 1990.

14. Miquel, J.; Economos, A. C.; Fleming, J.; Johnson, J. E. Jr. Mitochondrial role in cell aging. Exp. Gerontol. 15:575-591; 1980.

15. Ozawa, T. Mitochondrial DNA mutations associated with aging and degenerative diseases. Exp. Gerontol. 30:269-290; 1995.

16. Pannese, E. Neurocytology. Fine structure of neurons, nerve processes, and neuroglial cells. Stuttgart/New York: Georg Thieme Verlag; 1994.

17. Peters, A.; Vaughan, D. W. Central nervous system. In: Johnson, J. E. Jr., ed. Aging and cell structure, vol. 1. New York/London: Plenum Press; 1981:1-34.

18. Rosenberg, S. I.; Malmgren, L. T.; Woo, P. Age-related changes in the internal branch of the rat superior laryngeal nerve. Arch. Otolaryngol. Head Neck Surg. 115:78-86; 1989.

19. Sylvia, A. L.; Rosenthal, M. Effects of age on brain oxidative metabolism in vivo. Brain Res. 165:235-248; 1979.
20. Tauchi, H.; Sato, T. Age changes in size and number of mitochondria of human hepatic cells. J. Gerontol. 23:454-461; 1968.

21. Vanneste, J.; van den Bosch de Aguilar, Ph. Mitochondrial alterations in the spinal ganglion neurons in ageing rats. Acta Neuropathol. 54:83-87; 1981

22. Vega, J. A.; Calzada, B.; Del Valle, M. E. Age-induced changes in the mammalian autonomic and sensory ganglia. In: Amenta, F., ed. Aging of the autonomic nervous system. Boca Raton: CRC Press; 1993:3767.

23. Wallace, D. C. Diseases of the mitochondrial DNA. Annu. Rev. Biochem. 61:1175-1212; 1992.

24. Walter, P. B.; Beckman, K. B.; Ames, B. N. The role of iron and mitochondria in aging. In: Cadenas, E.; Packer, L., eds. Understanding the process of aging. The roles of mitochondria, free radicals, and antioxidants. New York/Basel: Marcel Dekker; 1999:203-227.

25. Weisbroth, S. H.; Flatt, R. E.; Kraus, A. L. The biology of the laboratory rabbit. New York/San Francisco/London: Academic Press; 1974.

26. Wilson, P.; Franks, L. M. The effect of age on mitochondrial ultrastructure. Gerontologia, 21:81-94; 1975. 